\title{
Clinical, Surgical and Histopathologic Outcomes of Filipino Patients with Micropapillary Thyroid Carcinoma in a Tertiary University Hospital in the Philippines
}

\author{
Ruby Jane Guerrero, ${ }^{1}$ Chandy Lou Malong, ${ }^{1}$ Jean Abigaile Caringal, ${ }^{1}$ \\ Cherry Sio, ${ }^{2}$ Vanessa Grace De Villa, ${ }^{3}$ Sjoberg Kho ${ }^{1}$ \\ ${ }^{1}$ Section of Endocrinology, Diabetes and Metabolism, University of Santo Tomas Hospital, Manila, Philippines \\ ${ }^{2}$ Department of Surgery, University of Santo Tomas Hospital, Manila, Philippines \\ ${ }^{3}$ Department of Pathology, University of Santo Tomas Hospital, Manila, Philippines
}

\begin{abstract}
Objective. Micropapillary thyroid carcinoma (micro-PTC) has a good prognosis but a number of cases will present with aggressive behavior. This study aims to determine the clinical outcomes with surgical management and histopathologic characteristics of Filipino patients with micro-PTC at University of Santo Tomas Hospital.

Methodology. 139 patients were diagnosed with micro-PTC from the year 2004-2011. Seventy five patients had complete data and were included in this retrospective study. Chi square test with Yates correction, T-test for tumor diameter, statistical means and percentages were used in data analysis.

Results. A total of 1,689 thyroid surgeries were done between 2004 and 2011. There were 1,054 patients (62.4\%) diagnosed with benign thyroid tumor(s) and 635 patients (37.6\%) with well-differentiated thyroid carcinoma. Of these, $139(22 \%)$ patients have micro-PTC. The prevalence rate of micro-PTC was $22 \%$, with a female predominance (86.6\%). The patients' ages ranged from 24-80 years old with a mean age of 47 years. Comparison of groups showed that having either incidental or non-incidental micro-PTC is independent of the clinical variables of the patient. Two (2.6\%) patients initially presented with cranial and supraclavicular metastasis. This study had a low recurrence rate $(5.3 \%)$ and a mortality rate of $1.3 \%$.
\end{abstract}

Conclusion. Male gender is the only significant variable for lymph node and distant metastasis. The patient's age, family history of cancer, number of foci, size and histological type of tumor have no prognostic value.

Key words: micropapillary thyroid carcinoma, radioactive iodine, thyroidectomy

\section{INTRODUCTION}

Micropapillary thyroid carcinoma (micro-PTC), defined as $<10 \mathrm{~mm}$ in its greatest diameter ${ }^{1}$ has been detected with increasing frequency after 1990 with the widespread use of sensitive diagnostic techniques such as neck ultrasound. ${ }^{2}$ Certain sonographic features of thyroid nodules associated with malignancy include hypoechogenicity, increased vascularity, microcalcifications, irregular margins, and the absence of a halo. ${ }^{3}$ It has been recommended that only nodules $>1 \mathrm{~cm}$ be evaluated through fine needle aspiration biopsy (FNAB) because of a greater potential to be clinically significant cancers. Patients with nodules $<1 \mathrm{~cm}$ with suspicious ultrasound findings, history of head and neck irradiation or a positive family history of thyroid cancer are advised further work up as well. ${ }^{4}$ However, some small nodules may lack the early warning signs of malignancy, yet may cause morbidity and mortality.

\section{e-ISSN 2308-118x}

Printed in the Philippines

Copyright (C) 2014 by the JAFES

Received January 30, 2014. Accepted May 5, 2014.
Thyroid cancers have an indolent course and a favorable prognosis, and with long-term survival rates of more than $90 \%, 5$ benefit of early diagnosis of this disease is uncertain, ${ }^{6}$ but many researchers believe treatment at an early stage reduces recurrence and mortality. ${ }^{7,8}$

Numerous risk factors for thyroid cancer, such as radiation exposure, age, and sex, have been welldocumented. ${ }^{9,10}$ Several epidemiologic studies have likewise demonstrated a significant variance in the incidence of thyroid cancer between ethnic groups; Filipino patients experienced a thyroid cancer recurrence rate of $25 \%$ compared with $9.5 \%$ for non-Filipino patients. ${ }^{11}$ Awareness of the factors that confer tumor aggressiveness coupled with the high prevalence of papillary thyroid cancer (PTC) among Filipinos may justify early detection and a more initial aggressive management and follow-up regimen in our population.
Corresponding author: Ruby Jane S. Guerrero, MD

University of Santo Tomas Hospital

Section of Endocrinology and Metabolism

St. Thomas Diabetes Center, USTH, Private Division

España, Manila, Philippines

Tel. No.: (+632) 731-3001 local 2455

Fax No.: (+632) 7810802

E-mail: janie_guerreromd@yahoo.com 
The optimal surgical treatment and use of radioactive iodine ablation in micro-PTC remains controversial. Recurrence of this disease has been detected at a mean of 2.8 years after primary treatment in as high as $6.2 \%$ of the population studied by Ross et al., with no difference among patients with unifocal or multifocal disease..$^{20}$ In our local setting, studies are limited by the small sample size and inadequate patient data thus, only supporting factors can be deduced. ${ }^{21}$ Association of risk factors and recommendations on the management of micro-PTC among Filipinos are lacking. Thus, it is the objective of our study to determine the clinical outcomes with the surgical management and histopathologic characteristics of Filipino patients with micropapillary thyroid carcinoma at University of Santo Tomas Hospital.

\section{METHODOLOGY}

This is a retrospective study involving Filipino patients diagnosed with micro-PTC at the University of Santo Tomas Hospital (USTH), a tertiary hospital which includes a 460-bed clinical division and 352-bed private division. All patients diagnosed with micro-PTC from year 20042011 were included in the study; those with incomplete data were excluded. Out of 139 patients diagnosed with micro-PTC, only 75 had complete data. The complete list of patients was taken from endocrine, surgical logbooks with $100 \%$ retrieval rate and supplemented by endocrine and histopathology logbooks. We retrospectively followed them at our outpatient department and at the consultants' private clinics. A data collection form was used to gather data which included patients' clinical and histopathologic profile, pre-operative work up, treatment and surgical procedures done, post-operative monitoring and clinical outcomes (Appendix A). Chi square test with Yates correction, T-test for tumor diameter, statistical means and percentages were used in data analysis.

\section{RESULTS}

A total of 1,689 thyroid surgeries were done between 2004 and 2011. There were 1,054 patients (62.4\%) diagnosed with benign thyroid tumor and 635 patients $(37.6 \%)$ with well-differentiated thyroid carcinoma. One hundred thirty nine $(22 \%)$ patients have micro-PTC. Shown in Table 1 is the clinical profile of patients with micro-PTC. The patients' age ranged from 24-80 years old with a mean age of 47 years, with a female predominance (86.6\%). Forty one patients $(54.6 \%)$ are $\geq 45$ years old with only four patients $(5.3 \%)$ having family history of thyroid cancer. Anterior neck mass was present for $\geq 5$ years in 23 patients (30.6\%). Based on thyroid function most patients (90.6\%) were noted to be euthyroid. Multinodular non-toxic goiter was present in 59 patients $(78.6 \%)$ and 7 (9.3\%) of them had multinodular toxic goiter. Features suspicious for malignancy like calcifications, were noted in 11 patients $(14.6 \%)$ and 4 patients $(5.3 \%)$ had hypoechoic nodules. FNAB results were as follows: 16 patients (21.3\%) adenomatous goiter, 15 (20\%) follicular lesion and 12 $(16 \%)$ papillary thyroid cancer.

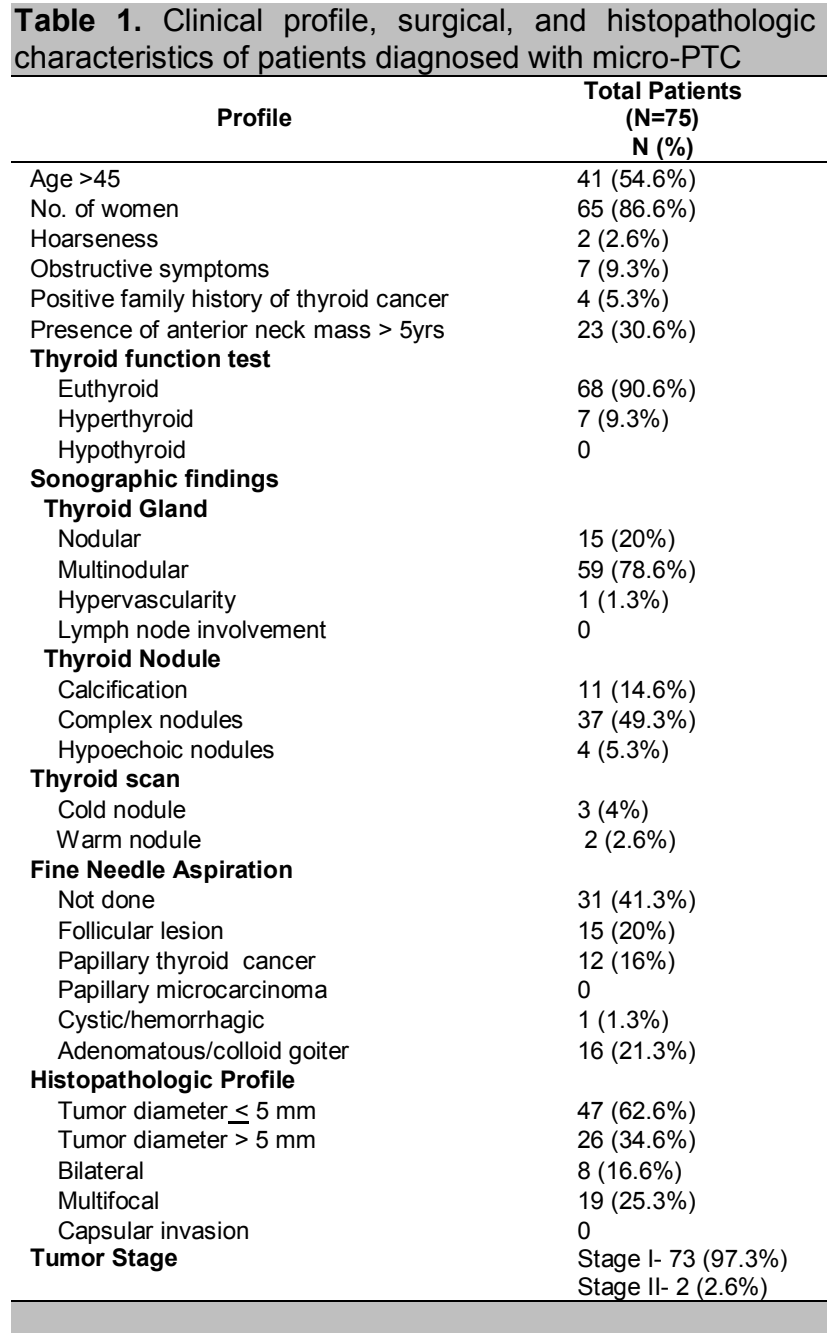

The majority of patients underwent total thyroidectomy $(89.3 \%)$, five patients $(6.6 \%)$ underwent near total thyroidectomy, three patients $(4 \%)$ underwent subtotal thyroidectomy and 1 had lobectomy. Ten patients (13.3\%) had modified radical neck dissection (MRND) and 1 with central lymph node (CLND) dissection. Postoperatively, 13 patients $(17.3 \%)$ had symptomatic, transient hypocalcemia; post-thyroidectomy hemorrhage occurred in 1 patient which required surgical evacuation. In our institution, indications for total thyroidectomy include multiple nodules, compressive symptoms, progressive increase in size of thyroid nodules and if FNAB is suspicious for malignancy. In histopathology report, most patients $(62.6 \%)$ had tumor diameter of $\leq 5 \mathrm{~mm}$, multifocality was seen in 19 patients $(25.3 \%)$ and 8 patients $(16.6 \%)$ had bilateral tumor. Only $2(2.6 \%)$ patients had Stage II tumor (T1N1bM1) and the rest have Stage I (T1N0M0) disease.

Non-incidental tumor (FNAB of a thyroid nodule was diagnostic/suspicious for malignancy) accounts for $50.6 \%$ of cases and the rest were incidental tumors (incidentally discovered during thyroid surgery for goiter or other 
benign disorder) at $49.3 \%$. Comparison of both groups showed that having either incidental or non-incidental micro-PTC is independent of the clinical variables of the patients (Table 2).

Table 2. Clinical profile and histopathologic characteristics of patients diagnosed with incidental versus non-incidental micro-PTC

\begin{tabular}{|c|c|c|c|}
\hline Profile & $\begin{array}{c}\text { Nonincidental } \\
\text { microPTC } \\
(\mathrm{N}=38) \\
\mathrm{N}(50.6 \%)\end{array}$ & $\begin{array}{c}\text { Incidental } \\
\text { microPTC } \\
(\mathrm{N}=37) \\
\mathrm{N}(49.3 \%)\end{array}$ & $\begin{array}{c}P \\
\text { value }\end{array}$ \\
\hline Age $>45$ & $21(55.2 \%)$ & $20(54 \%)$ & 0.916 \\
\hline No. of women & $31(55.2 \%)$ & $34(91.9 \%)$ & 0.33 \\
\hline Hoarseness & $1(2.6 \%)$ & $1(2.7 \%)$ & 0.485 \\
\hline Obstructive symptoms & $4(10.5 \%)$ & $3(8.1 \%)$ & 0.97 \\
\hline $\begin{array}{l}\text { Positive family history of } \\
\text { thyroid cancer }\end{array}$ & $3(7.9 \%)$ & $1(2.7 \%)$ & 0.626 \\
\hline $\begin{array}{l}\text { Presence of anterior neck } \\
\text { mass }>5 y \text { ys }\end{array}$ & $9(23.7 \%)$ & $14(37.8 \%)$ & 0.183 \\
\hline \multicolumn{4}{|l|}{ Thyroid function test } \\
\hline Euthyroid & $35(92.10 \%)$ & $33(89.2 \%)$ & 0.97 \\
\hline Hyperthyroid & $3(7.8 \%)$ & $4(10.8 \%)$ & \\
\hline \multicolumn{4}{|l|}{ Sonographic findings } \\
\hline Nodular & $9(23.7 \%)$ & $6(16.2 \%)$ & 0.418 \\
\hline Multinodular & $28(73.7 \%)$ & $31(83.8 \%)$ & 0.285 \\
\hline Hypervascularity & $1(2.6 \%)$ & 0 & 0.989 \\
\hline \multicolumn{4}{|l|}{ Thyroid Nodule } \\
\hline Calcification & $4(10.5 \%)$ & $7(18.9 \%)$ & 0.304 \\
\hline Complex nodules & $16(42.10 \%)$ & $11(29.7 \%)$ & 0.264 \\
\hline Hypoechoic nodules & $2(5.2 \%)$ & $2(2.7 \%)$ & 0.626 \\
\hline \multicolumn{4}{|l|}{ Thyroid scan } \\
\hline Cold nodule & $1(2.6 \%)$ & $2(5.4 \%)$ & 0.981 \\
\hline Warm nodule & $1(2.6 \%)$ & $1(2.1 \%)$ & 0.485 \\
\hline \multicolumn{4}{|l|}{ Fine Needle Aspiration } \\
\hline Not done & $8(21 \%)$ & $23(62.1 \%)$ & NA \\
\hline Follicular lesion & $15(39.7 \%)$ & 0 & \\
\hline Papillary thyroid cancer & $12(31.5 \%)$ & 0 & \\
\hline Cystic/hemorrhagic & 0 & $1(2.7 \%)$ & \\
\hline $\begin{array}{l}\text { Adenomatous / } \\
\text { colloid goiter }\end{array}$ & $3(7.8 \%)$ & $13(35.1 \%)$ & \\
\hline \multicolumn{4}{|l|}{ Histopathologic Profile } \\
\hline Tumor diameter $\leq 5 \mathrm{~mm}$ & $23(60.5 \%)$ & $24(63.1 \%)$ & 0.697 \\
\hline Tumor diameter $>5 \mathrm{~mm}$ & $13(34.2 \%)$ & $13(35.1 \%)$ & \\
\hline Bilateral & $4(10.5 \%)$ & $4(10.8 \%)$ & 0.738 \\
\hline Multifocal & $7(18.4 \%)$ & $12(32.4 \%)$ & 0.163 \\
\hline & Stage 1- 36 & Stage I- 37 & \\
\hline Tumor Stage & $\begin{array}{l}(54.7 \%) \\
\text { Stage II- } 2 \\
(5.2 \%)\end{array}$ & Stage II- 0 & 0.485 \\
\hline
\end{tabular}

In this study, two patients (2.6\%) initially presented with both lymph node and distant metastasis (brain and supraclavicular metastasis). Both patients are male, $\leq 45$ years old and biochemically euthyroid (Table 3). There was no reported compressive symptoms, no family history of thyroid cancer and the anterior neck mass was present for $\leq 5$ years. No abnormal sonographic feature was identified. On histopathology, tumor diameter is $\leq 5 \mathrm{~mm}$ and had classic papillary appearance. Bilateral disease was noted in the patient with a supraclavicular mass. Both have an average follow-up of 4 years. Our patient who presented with brain metastasis died after 4 years of follow up. Based on these variables, outcomes indicate that patients with lymph node and distant metastasis were likely to be male $(\mathrm{p}<0.05)$.

Shown in Table 4 are four patients $(5.3 \%)$ with tumor recurrence. Two (2.6\%) had $\geq 5$ years of follow up upon the detection of recurrence. Three $(4 \%)$ had tumor diameter of $\leq 5 \mathrm{~mm}$ and classic papillary on histopathology. All underwent total thyroidectomy followed by radioactive iodine (RAI) remnant ablation. Initial RAI dose given was between 30-100 mCi. Recurrence of tumor was detected on repeat ultrasound during follow up at 6-12 months after the initial surgery and was subjected to second RAI ablation with a mean dose of $57.5 \mathrm{mCi}$. Post-therapy whole body scan showed no evidence of distant metastasis for all 4 patients. Mean TSH levels on follow up were at therapeutic level of $\geq 0.1 \mathrm{uIU} / \mathrm{ml}$. No mortality was seen in both groups. Results indicate that patients with thyroglobulin $(\mathrm{TG})>2 \mathrm{mg} / \mathrm{ml}$ were more likely to have tumor recurrence $(\mathrm{p}<0.0001)$.

Table 3. Clinical and histopatholigc characteristics of patients with or without extra-thyroidal metastases at initial presentation of patients with micro-PTC

\begin{tabular}{|c|c|c|c|c|}
\hline Profile & $\begin{array}{c}\text { Without } \\
\text { lymph node } \\
\text { or distant } \\
\text { metastases } \\
(\mathrm{N}=73) \\
\mathrm{N}(97.3 \%) \\
\end{array}$ & $\begin{array}{c}\text { With lymph } \\
\text { node } \\
\text { metastases } \\
(\mathrm{N}=2) \\
\mathrm{N}(2.6 \%)\end{array}$ & $\begin{array}{c}\text { With } \\
\text { distant } \\
\text { metastases } \\
(\mathrm{N}=2) \\
\mathrm{N}(2.6 \%)\end{array}$ & P Value \\
\hline Age $>45$ & $39(53.4 \%)$ & 0 & 0 & 0.41385 \\
\hline No. of women & $63(86.3 \%)$ & 0 & 0 & 0.01057 \\
\hline No. of male & $10(13.7 \%)$ & 2 & 2 & $<0.05$ \\
\hline Hoarseness & $2(2.6 \%)$ & 0 & 0 & 0.05052 \\
\hline $\begin{array}{l}\text { Obstructive } \\
\text { symptoms }\end{array}$ & $2(2.6 \%)$ & 0 & 0 & 0.05052 \\
\hline $\begin{array}{l}\text { Positive family } \\
\text { history of } \\
\text { thyroid cancer }\end{array}$ & $4(5.4 \%)$ & 0 & 0 & 0.2187 \\
\hline $\begin{array}{l}\text { Presence of } \\
\text { anterior neck } \\
\text { mass }>5 \text { years }\end{array}$ & $19(26 \%)$ & 0 & 0 & 0.97322 \\
\hline \multicolumn{5}{|c|}{ Thyroid function test } \\
\hline Euthyroid & $65(89 \%)$ & 2 & 2 & 0.38096 \\
\hline Hyperthyroid & $6(8.2 \%)$ & 0 & 0 & \\
\hline \multicolumn{5}{|c|}{ Sonographic findings } \\
\hline Nodular & $11(15 \%)$ & 1 & 1 & 0.74045 \\
\hline Multinodular & $60(82.2 \%)$ & 1 & 1 & \\
\hline \multicolumn{5}{|l|}{ Thyroid Nodule } \\
\hline Calcification & $27(37 \%)$ & 0 & 0 & 0.72181 \\
\hline Complex nodules & $3(4.1 \%)$ & 0 & 0 & 0.13128 \\
\hline $\begin{array}{l}\text { Hypoechoic } \\
\text { nodules }\end{array}$ & $1(1.3 \%)$ & 0 & 0 & 0.0355 \\
\hline \multicolumn{5}{|l|}{ Thyroid scan } \\
\hline Cold nodule & $4(5.4 \%)$ & 0 & 0 & 0.2187 \\
\hline Warm nodule & $2(2.7 \%)$ & 0 & 0 & 0.05052 \\
\hline \multicolumn{5}{|c|}{ Fine Needle Aspiration } \\
\hline Not done & $31(42.4 \%)$ & 0 & 0 & NA \\
\hline Follicular Lesion & $15(20.5 \%)$ & 0 & 0 & \\
\hline $\begin{array}{l}\text { Papillary } \\
\text { Thyroid Cancer }\end{array}$ & $12(16.4 \%)$ & 2 & 2 & \\
\hline $\begin{array}{c}\text { Adenomatous / } \\
\text { colloid goiter }\end{array}$ & $13(18 \%)$ & 0 & 0 & \\
\hline \multicolumn{5}{|c|}{ Histopathologic Profile } \\
\hline \multicolumn{5}{|c|}{ Tumor diameter } \\
\hline$<5 \mathrm{~mm}$ & $40(54.8 \%)$ & 2 & 2 & 0.58752 \\
\hline$\geq 5 \mathrm{~mm}$ & $33(45.2 \%)$ & 0 & 0 & \\
\hline Bilateral & $7(9.5 \%)$ & 1 & 1 & 0.5192 \\
\hline Multifocal & $19(26 \%)$ & 1 & 1 & 0.9386 \\
\hline \multicolumn{5}{|c|}{ Histopathologic type } \\
\hline Classic & $66(90.4 \%)$ & 2 & 2 & NA \\
\hline Follicular variant & $4(5.4 \%)$ & 0 & 0 & \\
\hline Oncocytic variant & $1(1.3 \%)$ & 0 & 0 & \\
\hline Tumor Stage & $\begin{array}{l}\text { Stage I- } 73 \\
(100 \%)\end{array}$ & Stage II- 2 & Stage II- 2 & NA \\
\hline
\end{tabular}


Table 4. Correlation of surgical procedure done with or without radioactive ablative therapy among patients with or without tumor recurrence on follow up of patients with micro-PTC

\begin{tabular}{|c|c|c|c|}
\hline Treatment & $\begin{array}{c}\text { Patients } \\
\text { without } \\
\text { tumor } \\
\text { recurrence } \\
(\mathrm{N}=71) \\
\mathrm{N}(94.6 \%) \\
\end{array}$ & $\begin{array}{c}\text { Patients } \\
\text { with tumor } \\
\text { recurrence } \\
(\mathrm{N}=4) \\
\mathrm{N}(5.3 \%)\end{array}$ & $P$ value \\
\hline \multicolumn{4}{|c|}{$\begin{array}{l}\text { Duration of follow-up upon detection of } \\
\text { disease recurrence/persistence }\end{array}$} \\
\hline$\leq 5$ year & $63(88.7 \%)$ & 2 & \multirow[t]{2}{*}{ NA } \\
\hline$\geq 5$ years & $8(11.2 \%)$ & 2 & \\
\hline \multicolumn{4}{|l|}{ Tumor diameter } \\
\hline$\leq 5 \mathrm{~mm}$ & $39(55 \%)$ & 3 & \multirow[t]{2}{*}{0.6002} \\
\hline$\geq 5 \mathrm{~mm}$ & $5(7 \%)$ & 1 & \\
\hline \multicolumn{4}{|l|}{ Histopathologic type } \\
\hline Classic & $67(94.3 \%)$ & 3 & \multirow[t]{3}{*}{ NA } \\
\hline Follicular variant & $3(4.2 \%)$ & 1 & \\
\hline Oncocytic variant & $1(1.4 \%)$ & 0 & \\
\hline \multicolumn{4}{|l|}{ Surgical procedure done } \\
\hline Lobectomy & $1(1.4 \%)$ & 0 & \multirow[t]{4}{*}{ NA } \\
\hline Subtotal thyroidectomy & $3(4.2 \%)$ & 0 & \\
\hline Near total thyroidectomy & $5(7 \%)$ & 0 & \\
\hline Total thyroidectomy & $62(87.3 \%)$ & 4 & \\
\hline \multicolumn{4}{|c|}{ Radioactive lodine Ablation (RAI) } \\
\hline Surgery wd RAI & $32(45 \%)$ & 4 & \multirow[t]{2}{*}{0.10412} \\
\hline Surgery only & $39(55 \%)$ & 0 & \\
\hline Dose $<100$ & $7(9.8 \%)$ & 0 & \multirow[t]{2}{*}{0.47454} \\
\hline Dose $\geq 100$ & $25(35.2 \%)$ & 1 & \\
\hline \multicolumn{4}{|l|}{ Mean TSH levels } \\
\hline$<0.1$ & 0 & 0 & \multirow[t]{2}{*}{ NA } \\
\hline$\geq 0.1$ & $71(100 \%)$ & 4 & \\
\hline \multicolumn{4}{|l|}{ Diagnostic Monitoring } \\
\hline Thyroid ultrasound & $71(100 \%)$ & 4 & NA \\
\hline Thyroglobulin $>2 \mathrm{mg} / \mathrm{mL}$ & 0 & 4 & \multirow{2}{*}{0.0001} \\
\hline Whole body scan & 0 & 4 & \\
\hline
\end{tabular}

\section{DISCUSSION}

There have been many reports from various countries describing micro-PTC detected at autopsy and the prevalence rates have ranged from $6.0-35.6 \%$. One of the largest meta-analysis done on micro-PTC reported a prevalence to be largely ranging from $0.01 \%$ in USA to $35.6 \%$ in Finland, the highest reported value in the literature to date. ${ }^{20}$ This striking difference may be due to genetic and environmental factors and the methods employed in the histologic examination of the thyroid gland. Among Asians, the Japanese have had consistently elevated prevalence of micro-PTC at around 13.7-28.4\%, which many experts believe to be related to the radiation exposure during the bombing of Hiroshima and Nagasaki. In Hongkong, micro-PTC has also increased over time among well differentiated thyroid cancers, with 5.1\% before 1980 and recently at $21.7 \%$ in $1991-2000 .^{20}$

The pilot study done on clinical outcomes of micro-PTC among Filipinos by Silva in 2009, reported a $10 \%$ prevalence of micro-PTC among well differentiated thyroid cancers. ${ }^{14}$

This study has a $22 \%$ micro-PTC prevalence rate and had female predominance $(86.6 \%)$. Combining the results of different studies, most patients were women and this may be due to their higher prevalence of thyroid disease and, therefore, greater access to diagnostic procedures resulting in increased identification of this type of cancer. The increasing proportion of micro-PTC may be attributed to the more frequent use and improvement of ultrasonography, fine needle aspiration biopsy and pathology procedures. ${ }^{15-23}$

Taking into account the presentation, micro-PTC can be divided into "incidentally" and "non-incidentally" detected tumor. The definition of both terms however has not been standardized. The result of different studies showed that $71 \%$ of micro-PTC is incidentally discovered at surgery for other thyroid disorders. The prevalence is variable ranging in large series between $4.6 \%$ and $100 \%$ which may be due to variable use and expertise in ultrasonography in different countries. ${ }^{20}$ Studies also have shown that non-incidental tumor is more frequently associated with poor prognostic factors such as multifocality or capsular invasion and a higher rate of local or distant spread. ${ }^{20-21}$ This study has $50.6 \%$ rate of non-incidental tumors and when compared with incidental tumors, it showed no significant differences in terms of clinical and histopathologic characteristics of the patients. Literature reports multifocality is present in 30$40 \%$ of cases, whereas bilateral disease is found in around $20 \%$ of involved glands. ${ }^{16}$ In our patients, multifocality was seen in $18.4 \%$, with one patient with distant metastasis and recurrent disease.

Distant metastasis at diagnosis for micro-PTC is rare. Only a few studies have statistically analyzed risk factors associated with it. ${ }^{16,19-21}$ The reported common metastatic sites for micro-PTC were cervical lymph nodes, submandibular salivary glands, lungs, skeleton and the brain. Lymph node metastases and extrathyroid extension are observed in $4.4 \%$ and $25.7 \%$, respectively in patients with micro-PTC $\leq 5 \mathrm{~mm}$ in diameter and death related to micro-PTC has been reported in very few cases..$^{21}$ According to Roti, distant metastasis correlated positively with the diameter of tumor, advancing age, lymph node metastasis at diagnosis and follicular variant of microPTC. We reported 2 patients with lymph node and distant metastases, presenting with cranial and supraclavicular masses. However, they did not coincide with the reported high risk factors, as both of them are $\leq 45$ years old, with tumor diameter of $\leq 5 \mathrm{~mm}$ and is of papillary type. This study only had 1 mortality in a patient who presented with distant metastasis to the brain.

Most series of patients with micro-PTC have reported low cancer recurrence rates although this finding has not been universal. ${ }^{16,19,21}$ During follow-up, we have observed only 4 patients $(5.3 \%)$ with recurrent disease and no reported mortality. All had total thyroidectomy for unifocal disease. RAI remnant ablation was given post-operatively, with a mean dose of $57 \mathrm{mCi}$. In a multivariate analysis done by Baudin, only two parameters were found to influence recurrence: the number of micro-PTC foci at pathologic examination and the extent of thyroid surgery. They found 
the recurrence rate for patients with unifocal disease is $1.2 \%$ compared with $8.6 \%$ for patients with multifocal disease..$^{21}$

Surgical procedures in patients with micro-PTC greatly vary among studies. From the meta-analysis of Roti, total/near total thyroidectomy was performed in $72 \%$, subtotal thyroidectomy in $11 \%$ and lobectomy in $7 \%$ of cases. ${ }^{20}$ Similarly, most of our patients $(88 \%)$ also underwent total thyroidectomy, 10 of them had MRND and 1 patient had CLND. Two studies showed a recurrence rate of $2.3 \%-5 \%$ for patients with multifocality undergoing total thyroidectomy, whereas lobectomy and/or isthmusectomy had higher recurrence rate at 8.225\%. ${ }^{21,23}$ Moreover, data from the National Thyroid Cancer treatment Cooperative Study Group registry (NTCTCSR) found that with lobectomy, recurrences were more common with multifocal disease than unifocal lesions. On the other hand, one author recommended that patients with micro-PTC that are not associated with unfavorable features can be candidates for observation regardless of their background and clinical features. ${ }^{18}$

It is unclear whether micro-PTC size plays a role in prognosis. Some data indicate a higher recurrence rate associated with lesions larger than $5 \mathrm{~mm}$ in comparison to smaller foci. ${ }^{8}$ However, this association is not a consistent finding. Chow et al., have reported that the incidence rate of local and lymph node recurrence in patients with microPTC did not differ between patients with cancers $\leq 5 \mathrm{~mm}$ compared with those $\geq 5 \mathrm{~mm} .{ }^{23}$ Pelizzo et al., did not mention any difference in aggressiveness between patients whose tumors had diameter $>5 \mathrm{~mm}$ compared with those smaller than $5 \mathrm{~mm} .{ }^{12}$ In addition, according to Pellegriti, tumor size is not a predictor of persistent/recurrent disease, because these tumors have indolent and slow progression and the differences in outcome may be seen only after a longer follow up. ${ }^{22}$ In our study, 3 of 4 patients with recurrent disease had $\leq 5 \mathrm{~mm}$ tumor diameter size. The mean follow up for our patients was 5 years, which may have allowed the discovery of recurrence in our patients. Consistent with other studies, our result showed a low recurrence rate $(5.3 \%)$ and does not affect patient survival.

Radioactive Iodine (RAI) ablation may also be indicated after near/total thyroidectomy to destroy remaining thyroid remnant after surgery. ${ }^{4,16}$ This procedure will also increase the accuracy of serum thyroglobulin (TG) as a predictor of relapsing/persisting disease. The benefit of RAI ablation is unclear especially for low risk patients since recent data showed that there is no decrease in recurrence with the use of RAI..$^{19,23}$ The studies of Pelizzo and Chow both showed that those who underwent RAI after surgery had lower recurrence rate. ${ }^{12,23}$ In contrast, Baudin found that RAI did not affect the recurrence rate in micro-PTC. ${ }^{21}$ In our institution, only $45 \%$ of patients underwent RAI after surgery, since there is no definite guidelines on the use of RAI and the decision to give such treatment is based mainly on the clinical judgment of the attending physician. But most experts agreed that RAI ablation is given in cases where worrisome features are present such as local extension, distant metastasis or pulmonary involvement. ${ }^{16}$ Even in the absence of high risk features, we have 4 cases of recurrent disease and these patients underwent both total thyroidectomy and RAI ablation, supporting the report of Baudin. ${ }^{21}$ However, the low incidence of recurrence in our study does not preclude any conclusion regarding factors not found to be associated with recurrence.

From the 2009 ATA guidelines, the initial follow-up for low-risk patients who have undergone total or near-total thyroidectomy and RAI ablation is based mainly on thyroid stimulating hormone (TSH) -suppressed TG and cervical ultrasound, followed by TSH-stimulated serum TG measurements if the TSH-suppressed TG testing is undetectable. ${ }^{4}$ Suppression of TSH with levothyroxine has been used in thyroid cancer for decades. The ATA recommends that low-risk patients, a category that includes the majority of micro-PTC, be treated with levothyroxine to reach a serum concentration of $0.1 \mathrm{mU} / \mathrm{L}$ in the early follow up period and for maintenance treatment the goal is to have serum TSH values $0.1-0.5$ $\mathrm{mU} / \mathrm{L} \cdot{ }^{4,16}$ All of our patients were maintained on the same therapeutic level of $\mathrm{TSH} \geq 0.1 \mathrm{mU} / \mathrm{L}$ during the course of their follow up. After RAI, stimulated TG levels and whole body scan can be effectively used for surveillance. For patients who did not undergo RAI ablation, TG levels and whole body scan can be used during follow up. TG measurement at the first post-surgical evaluation after levothyroxine withdrawal is a strong prognostic factor. ${ }^{15-}$ 17,22 A serum TG of at least $1.0 \mathrm{ng} / \mathrm{ml}$ is considered diseasefree and has approximately $1 \%$ probability to develop local recurrences. ${ }^{22}$ Ultrasonography has been used for evaluating thyroid tumor post-operatively to monitor for recurrence in the lymph node or thyroid remnant. ${ }^{17}$ It is undoubtedly the most useful tool to assess lymph node status of micro-PTC. In this study, all patients underwent cervical ultrasound 6 months after surgery where recurrence was detected upon follow up.

\section{CONCLUSION}

As the use of high-resolution sonography and FNAB becomes more frequent, micro-PTC is being diagnosed with increasing incidence. In our institution, micro-PTC has a $22 \%$ prevalence rate. Overall, patients with microPTC have a good prognosis and carries a low risk for mortality, only $1.3 \%$ in this study. However, in some cases, it may present with aggressive behavior for which recurrence maybe high. Having a male gender is our only significant variable for lymph node and distant metastasis. Other predictors for recurrent disease is difficult to ascertain since the patient's age, family history of cancer, number of foci, size and histological type of tumor have no prognostic value based on our results. We still strongly 
recommend that future studies involve a much larger sample size in order to better capture the phenomenon.

There are no clinical guidelines on management of microPTC, so the approach varies among our physicians. Nevertheless, total thyroidectomy is still the initial treatment of choice for our patients but the use of RAI is not universal. Levothyroxine suppression to maintain TSH at therapeutic levels should be applied for all patients. Measure TG at first post-surgical follow up, since this has a strong prognostic value. Ultrasound for monitoring lymph node and thyroid remnant status for recurrence is a useful tool. More important, there is a need to emphasize longer follow-up since differences in outcome may only be seen after years of follow up due to their indolent course and slow progression.

\section{Acknowledgements}

We thank the following for their support: consultants, fellows and staff of the USTH Section of Endocrinology, Diabetes and Metabolism; Department of Surgery; Department of Pathology and the Medical Records section.

\section{References}

1. Hedinger C, Williams ED, Sobin LH. The WHO histological classification of thyroid tumours: A commentary on the second edition. Cancer.1989;63:908-11.

2. Elisei R, Molinaro E, Agate L. Single-Institution 35-Year Study on 4187 Patients. J Clin Endocrinol Metab. 2010; 95(4):1516-1527.

3. Fish SA, Langer JE, Mandel SJ. Sonographic imaging of thyroid nodules and cervical lymph nodes. Endocrinol Metab Clin N Am. 2008; 37:401-417.

4. Cooper DS, Doherty GM, Haugen BR, et al. Revised American Thyroid Association guidelines for patients with thyroid nodules and differentiated thyroid cancer. Thyroid. 2009; 19:1167-1214.

5. Lundgren CI, Hall P, Dickman PW, Zedenius J. Influence of surgical and postoperative treatment on survival in differentiated thyroid cancer. Br J Surg. 2007; 94(5):571-577.

6. Frates $\mathrm{MC}$, Benson $\mathrm{CB}$. Society of radiologists in ultrasound management of thyroid nodules detected at US: Society of radiologists in ultrasound consensus conference statement. Radiology. 2005; 237:794-800.
7. Baskin HJ, Duick DS. The endocrinologists' view of ultrasound guidelines for fine needle aspiration. Thyroid. 2006; 16:207-208

8. Mazzaferri EL, Kloos RT. Clinical review 128: Current approaches to primary therapy for papillary and follicular thyroid cancer. J Clin Endocrinol Metab. 2001; 86:1447-1463.

9. Murray D. The thyroid gland, Functional endocrine pathology, 2nd ed. Malden: Blackwell Science, 1998.

10. Shah JP, Patel SG. Thyroid and parathyroid glands. In: Head and neck surgery and oncology, 3rd ed. Philadelphia: Mosby, 2003.

11. Kus HK, Shah M, Eski S, Walfish PG, Freeman JL. Thyroid cancer outcomes in Filipino patients. Arch Otolaryngol Head and Neck Surg 2010; 136 (2): 138-142.

12. Pelizzo MR, Boschin IM, Toniato. Papillary thyroid microcarcinoma (PTMC): Prognostic factors, management and outcome in 403 patients. Eur J Surg Oncol. 2006;32:1144-8.

13. Ross DS, Litofsky D, Ain KB, et al. Recurrence after treatment of micropapillary thyroid cancer. Thyroid. 2009; 19(10):1043-8.

14. Silva GA, Aragon JB. Clinical outcomes of papillary thyroid microcarcinoma in Filipino patients: A 12-year experience at Makati Medical Center. Phil J Internal Medicine. Nov-Dec 2009; 47: 237-244.

15. Pearce EN, Braverman LE. Editorial: Papillary thyroid microcarcinoma outcomes and implications for treatment. J Clin Endocrinol Metab. 2004; 89(8):3710-3712.

16. Bernet, V. Approach to the Patient with incidental papillary microcarcinoma, J Clin Endocrinol Metab. August 2010; 95(8): 35863592.

17. Ito, Y. Therapeutic strategy for papillary microcarcinoma of the thyroid. Curr Cancer Ther Rev. 2005; 1:19-25.

18. Ito $\mathrm{Y}$, Miyauchi A, Inoue $\mathrm{H}$, et al. An observational trial for papillary thyroid microcarcinoma in Japanese patients. World J Surg. January 2010; 34(1): 28-35.

19. Roti, E. Clinical and histological characteristics of papillary thyroid microcarcinoma: Results of the retrospective study in 243 patients. J Clin Endocrinol Metab. June 2006; 91(6): 2171-2178.

20. Roti E, degli Uberti EC, Bondanelli M, Braverman LE. Thyroid papillary microcarcinoma: A descriptive and meta-analysis study. Eur J Endocrinol.2008;159(6):659-673.

21. Baudin, E, Travagli JP, Ropers, J, et al. Microcarcinoma of the thyroid gland: The Gustave Roussy Institute experience. Cancer. 1998;83:553559 .

22. Pellegriti, G. Clinical behavior and outcome of papillary thyroid cancers smaller than $1.5 \mathrm{~cm}$ in diameter: Study of 299 Cases. J Clin Endocrinol Metab. August 2004; 89(8):3713-3720.

23. Chow SM, Law SCK, Chan JKC, Au SK, Yau S, Lau WH. Papillary microcarcinoma of the thyroid-prognostic significance of lymph node metastasis and multifocality. Cancer. 2003; 98:31-40.

Articles and any other material published in the JAFES represent the work of the author(s) and should not be construed to reflect the opinions of the Editors or the Publisher. Authors are required to accomplish, sign and submit scanned copies of the JAFES Declaration: that the article represents original material, that is not being considered for publication or has not been published or accepted for publication elsewhere. Consent forms, as appropriate, have been secured for the publication of information about patients; otherwise, authors declared that all means have been exhausted for securing such consent. The authors have signed disclosures that there are no financial or other relationships that might lead to a conflict of interest. All authors are required to submit Authorship Certifications that the manuscript has been read and approved by all authors, and that the requirements for authorship have been met by each author 